\title{
AGROFORESTRY SYSTEMS IN SRI LANKA: A SUSTAINABLE RESOURCE MANAGEMENT APPROACH
}

\author{
Mangala De Zoysa \\ Department of Agricultural Economics, \\ Faculty of Agriculture, University of Ruhuna, \\ Mapalana, Kamburupitiya.
}

To meet the increasing demands of growing population, Sri Lanka has to increase and sustain agricultural production. At the same time tree component of agriculture has become important for environmental conservation apart from the need for timber, fuel, fodder and non-wood products. Especially for more populated areas, integration of trees with crops is considered more useful and sustainable for environmental and economic reasons. Though the agro-forestry system in some parts of country is not a new adoption, the scientific and systematic study of this practice on one hand, and development of new management strategies for wider adoption on the other, is relatively new.

This paper attempts to discuss the potential of agro-forestry as a sustainable resource management system for Sri Lanka. Physical factors and government / institutional variables are considered as external determinants while personal, socio-economic and socio-psychological factors of individual farm family contribute as inputs of operation of the agro-forestry system. The agro-forestry system makes outputs/results in terms of subsistence, cash savings, farm improvements and cash costs for the individual farm family. Further, the paper describes the potential for system development through feedback, to change possible physical factors of individual farm family; and potential feedback, to change government / institutional variables under right political, social and institutional conditions. 